\title{
Understanding Sport Corruption: An Examination of People's Perceptions Toward Corruptions
}

\author{
Geumchan Hwang \\ Northern State University, Aberdeen, USA
}

\begin{abstract}
The purpose of this study was to examine: (1) the relationship between people's perceptions toward corruptions and magnitude of national corruption in a country; and (2) the relationship between people's perceptions toward corruptions and sport corruptions according to different levels of corruptions in sport. To examine the relationship, 110 corruption cases in sport and Corruption Perception Index (CPI) database between 2000 and 2010 were collected and analyzed. Results of study revealed: (1) there was a positive correlation between people's perceptions toward corruptions and magnitude of national corruptions; (2) there was a negative correlation between people's perceptions toward corruptions and sport corruptions; and (3) there was a mean difference of people's perceptions toward corruptions between individual level (e.g., individual match-fixing) of sport corruption and team level (e.g., team doping) of sport corruption. This study provides practical implications with administrators in sport organizations in that the results of study offered better understanding of how sport corruptions are serious and how to prevent and reform different levels of sport corruptions (individual, team, organization). Despite its contribution, this study has limitations because the study only analyzed 110 corruption cases between 2000 and 2010 and used defective corruption measurement, CPI. Thus, future research will examine sport corruptions using more appropriate measurement and will discuss how to prevent and reform corruptions in sport.
\end{abstract}

Keywords: sport corruption, national corruption, corruption perception index

\section{Introduction}

There is a paucity of research that focuses on the meaning of corruption for positively sustainable sports activities while corruption has been a significant issue due to its necessity for preventing potential problems caused by corruption in the context of sports. It has been posited that there are many numbers of cases (i.e., more than 2000 cases) in revealing the problems of corruption between 2001 and 2010 in a sports area (Gorse \& Chadwick, 2010). This may require industry practitioners and/or scholars to recognize the meaning of corruption in subsequent procedures: identifying potential reasons (e.g., motivation), determining consequences of corruption (e.g., penalty), and creating reforms (e.g., remedy) in long-term strategic planning (Ashforth \& Anand, 2003; Becker \& Stigler, 1974; Maennig, 2005, 2008; Myint, 2000; Treisman, 2000). Given this recognition, Myint (2000) addressed that corruption may occur across many countries, indicating that countries which host sports should recognize the significance of corruption occurred in the domain of sports.

Historically, the evidence of corruption in sports was first found in the case of the Olympic Games of 388 B.C. (Maennig, 2005), showing that it is not unusual phenomenon in our long history. Despite this, there is a

Geumchan Hwang, assistant professor, Northern State University. 
question why corruption still exists and cannot be removed. A number of scholars in sports management have attempted to solve the task, but it seems that we may still be in an assignment. However, a substantial study has proposed the necessity of rational approaches to deal with the occurrences of corruption in sports. For example, the most appropriate definition of corruption may enable us to understand the reason why corruption occurs in sports activities. In this regard, among various types of corruption definitions, a definition of corruption in sports has been primarily suggested as follows (Maennig, 2008).

Behavior by athletes who refrain from achieving the levels of performance normally required in the sports in question to win the competition and instead intentionally permit other to win, or behavior by sporting officials who consciously perform their allocated tasks in a manner at variance of the relevant club, association, competitive sports in general and/or society at large (pp. 2-3).

Despite the above definition has been widely used in the domain of sport, there is a lack of accepting its meaning within all contexts of sport due to ambiguous and unclear terms such as "unethical" or "immoral". Since every case of corruption in sports cannot be explained by those imperfect definitions, there have been controversial issues for interpreting the "unethical issue" in sports. This is a fundamental reason why the corruption in sport still exists and difficult to be removed. Nevertheless, it is evident that corruptions in sport arise all over the world. In particular, the corruption is manifest at the individual levels as an isolated event and at the group level in an organized form (Bac, 1998).

It is important to examine the degree of corruption in a country to figure out corruption in sport in that corruption is universal phenomenon regardless of group, culture or ethnicity. It is possible to presume how people's perceptions toward corruptions can be reflected on sport area. From the perspective, the purpose of this study is to examine: (1) the relationship between people's perceptions toward corruptions in society and magnitude of national corruption in a country; and (2) the relationship between people's perceptions toward corruptions in a society and sport corruptions.

\section{Literature Review}

\section{Understanding Corruption}

Corruption is generally defined as "the misuse of public office for private gain" (Treisman, 2000, p. 1) or "the misuse of authority for personal, subunit and/or organizational gain" (Ashforth \& Anand, 2003, p. 2). Myint (2000) also defined the corruption as "the use of public office for private gain, or use of official position, rank or status by an office bearer for own personal benefit" (p. 35). Despite general definitions, the concept of corruption is interpreted differently according to various types and forms (Andving \& Fjeldstad, 2001; Bac, 1998; Maennig, 2005, 2008; Tanzi, 1998).

In sport, Maennig (2008) defined sport corruption as "behaviors by athletes who refrain from achieving the levels of performance normally required in the sport in question to win the competition and instead intentionally permit others to win, or behavior by sporting officials who consciously perform their allocated tasks in a manner at variance with the objectives and moral values of the relevant club, association, competitive sports in general and/or society at large" (pp. 2-3). Based on Maennig's (2008) definition, Gorse and Chadwick (2010) proposed a new definition of corruption in sport as "any illegal, immoral or unethical activity that attempts to deliberately distort the result of a sporting contest for the personal material gain of one or more parties involved in that activity" (p. 43). Corruption in sport has been addressed extensively, but more clear 
understanding about "immortal" or "unethical" activity in sport is needed because it might be interpreted differently according to situational factors such as culture or social norms. Therefore, it is important to make clearly accountable definition in sports corruption study.

To understand more clear definition of corruption, Rabl and Kühlmann (2008) attempted to explain the concept of corruption as five dimensions: (1) Corruption is based on the interaction between at least two partners ("exchange") (Ashforth \& Anand, 2003; Heidenheimer, 2002; Höffling, 2002; Rabl \& Kühlmann, 2008); (2) Corruption is immoral behavior ("violation of norms") (Brasz, 1970; Van Duyne, 2001; Rabl \& Kühlmann, 2008); (3) Corrupt actors take advantage of authority, position or knowledge ("abuse of power") (Ashforth \& Anand, 2003; Huntington, 1989; Khan, 1996; Nye, 1967; Pitt \& Abratt, 1986; Tanzi, 1995, 1998; Treisman, 2000; Van Duyne, 2001; Rabl \& Kühlmann, 2008); (4) Victims are only found outside the corrupt case ("absence of direct victims") (Rabl \& Kühlmann, 2008; Von Arnim, 2003); and (5) Corrupt actors organize hidden relationship that can agree on the illegal or unethical behaviors in exchange for personal purpose ("secrecy") (Hacker, 1981; Rabl \& Kühlmann, 2008). The five dimensions of corruption have been used for understanding corrupt behaviors in sport. It is difficult to explain every corruption in sport with those imperfect definitions. Therefore, sport corruption should be restricted with clarity to avoid controversial issues with regard to corrupt behaviors in sport.

Corruption is regarded as a symptom of fundamental economic, political and institutional weaknesses and shortcomings in a country (Myint, 2000). In sport, corruption is an index which pertains to the degree of deviated sportsmanship in a country. Ashford and Anand (2003) addressed how ethically sound person become steeped in corruption and regarded the motivation of corruption as the internalized behavior through socialization. From the business perspective, Collins, Uhlenbruck, and Rodriguez (2009) studied why firms are involved in corruption. The study found the degree of managers' engagement with corruption is driven by their familiar ties to government officials, their perception of corruption as taken-for-granted, their involvement in political parties, and their affiliation with professional organizations (Collins et al., 2009).

Treisman (2000) focused on examining the causes of corruption through a cross-national study. According to Treisman's (2000) study, historical and cultural tradition, levels of economic development, political institutions, and government policies affect corruptions in a country. That is, corruptions occur over the world and it should be interpreted based on historical background, cultural difference, and tradition.

With regard to individual motivation of corruption, Zyglidopoulos and Fleming (2007) examined how individuals are identified with corrupt organizations and how individuals move from bystander status to guilty perpetrators. The results of study revealed the greater the distance between an act and its ethical consequences, the easier it will be for individuals within an organization to become innocent participants in corrupt activities. The study also showed that the greater the distance between an act and its ethical consequences, the more likely it will be that innocent participants will become rationalizers.

In sport, Ramos (2009) examined the current state of corruption in tennis and addressed several reasons of corruption in tennis. Those reasons include: (1) insufficient sanctions; (2) barriers to investigation; and (3) a lack of uniformity among the governing bodies' rules. The study suggested several ways (e.g., increasing sanctions, coordination with betting organizations, obligation to report suspected cases) to reform corruptions in sport.

Many studies (Ashford \& Anand, 2003; Collins et al., 2009; Zyglidopoulos \& Fleming, 2007; Myint, 2000; Ramos, 2009; Treisman, 2000) attempted to understand motivations of corruption. Findings of studies revealed the socialization and interaction with group members are main factors that affect corruption on ethical persons. 
In addition, studies (e.g., Treisman, 2000; Zyglidopoulos \& Fleming, 2007) also found other factors (e.g., culture, tradition, and individual preference) should be considered to understand motivations of corruption.

\section{Sport Corruption}

Researchers (e.g., Gorse \& Chadwick, 2010; Maennig, 2005, 2008) studied types of sport corruptions and how corrupt actions occur in sport. Maennig (2005) analyzed corruption cases occurred in sport and divided sport corruptions into two categories. The first category is about competition results, whereby the provider and the recipient of the bribes can be athletes only, sporting officials and other non-athletes such as referees, or athletes and officials. The second category is about the corruption related to sporting bodies and officials regarding host venue for important competitions, allocation of rights, or nomination for positions and so on.

Gorse and Chadwick (2010) divided the corruption in sports into four types: bribe, match-fixing, misuse of inside information for betting purpose, and doping. Gorse and Chadwick (2010) analyzed the 2,089 cases of corruption in sport for 10 years from 2000 to 2010 and found that most cases (95.64\%) were related to doping and many athletes used prohibited drugs in order to enhance performance in sport games (Gorse \& Chadwick, 2010). The finding also revealed match-fixing and misuse of inside information occurs when uncertainty and unpredictability of sport games vanish (Gorse \& Chadwick, 2010).

In sport, the corruption cases revealed to the public merely represent the tip of the iceberg (Maennig, 2005). The extent of corruption depends on the definition of corruption adopted, but it is generally used in the form of level or intensity of corruption. That is, it represents hierarchical level of corruption (e.g., individual, team, and organizational level of corruption), number of times occurred, or how long the corrupt behaviors lasted (Maennig, 2005).

With regard to reform of the corruption in sport, Maennig (2005) addressed how sport organizations should manage corrupt behaviors on-field (e.g., doping) and off-field (e.g., sexual misconduct). Maennig (2005) proposed the creation of clear codes of conduct with unambiguous definitions of behaviors, transparent procedure for the selection of sporting venues, financial incentive mechanisms for athletes and officials, and increase controls and penalties.

Mason, Thibault, and Misener (2006) also examined the reasons of corruption and how to reform corruptions in sport. In particular, Mason et al. (2006) addressed agency problems in sport organizations by reviewing the corruption case of the International Olympic Committee (IOC) and suggested delegating the control function of decision making to the IOC board and the management function to internal agents.

Despite numerous corruption studies in sport (Gorse \& Chadwick, 2010; Maennig, 2005, 2008; Mason et al., 2006), little attempts have been made to find a relationship between corrupt behaviors in sport and magnitude of national corruption in a country. If any, how the level of sport corruption (i.e., individual, team, and organization) is different according to the magnitude of national corruption in a country. Based on the literature, the following hypotheses were constructed:

Hypothesis 1: There is a positive correlation between people's perceptions toward corruptions and magnitude of corruptions in a country;

Hypothesis 2: There is a positive correlation between people's perceptions toward corruptions and sport corruptions;

Hypothesis 3: There is a mean difference of people's perceptions toward corruptions among three levels of sport corruption (i.e., individual, team, organization). 


\section{Method}

\section{Sample and Data Collection}

To examine the relationship between corruptions in sport and magnitude of national corruption in a country, corruptions in sport occurred from 2001 to 2010 and Corruption Perception Index (CPI) database were selected. Regarding sport corruptions, a total of 110 corruption cases were collected from Gorse and Chadwick's (2010) and Maennig's (2005) study. With respect to the magnitude of national corruption, CPI database from 2001 to 2010 was collected from Transparency International (TI) organization. CPI is an aggregated indicator that represents the extent to which corruptions are perceived to exist among public sectors (e.g., politicians, officials) and constructed based on different sources such as the World Economic Forum (WEF), the Institute for Management Development (IMD), and so on (Urra, 2007). Each country's CPI figure was matched with each corruption case in sport.

\section{Instrument}

Based on the documented corruption cases, each case was coded into six variables: year, sports type, continent, hierarchical level of corruption, intensity, and penalty. The sports variable divided into individual sports and team sports, and the continent variable was specified into six continents: Asia, Europe, North America, South America, Africa, and Oceania. The hierarchical level of corruption was classified into three levels. The first level was the individual corruption related to an individual athlete, a referee, or a coach. The second level of corruption was the team corruption conducted by two or more individuals (e.g., athletes, coaches) who were involved in corrupt behaviors. The last level of corruption was the organizational corruption manipulated by sport organizations. Intensity means duration period of each corruption case and the penalty variable divided into four types: no penalty, fine, disqualification, and find with disqualification. To measure magnitude of national corruption, CPI database from Transparency International (TI) organization were used.

\section{Data Analysis}

To analyze what types of corruption and penalty occurred according to types of sports and countries, content analysis was adopted. To examine the relationship between sport corruption and magnitude of national corruption, the correlation analysis was used. Lastly, one-way Analysis of Variance (ANOVA) was used to examine the difference of hierarchical level of corruption (i.e., individual, team, and organization) on CPI.

\section{Results}

Among 110 corruption cases (e.g., match-fixing, bribe, misuse of inside information), 54 cases (49.1\%) arose in Europe, followed by 21 cases $(19.1 \%)$ in Asia, 14 cases (12.7\%) in Oceania, 12 cases $(10.9 \%)$ in North America, 6 cases (5.5\%) in Africa, and 3 cases (2.7\%) in South America. In short, many of sport corruption cases (68.2\%) were occurred in Europe and Asia between 2001 and 2010. In terms of sports, most corruption cases occurred in team sports (63.6\%) such as football, basketball, and baseball rather than individual sports. With regard to penalty imposed on corrupt behaviors, $57.3 \%$ of corruptors were disqualified (i.e., sanction) temporarily or permanently, and $22.7 \%$ of corruptors were disqualified with fine.

Table 1 shows sport corruptions (i.e., match-fixing, bribe, misuse of inside information) according to level of corruptions (i.e., individual, team, organizational level) and there was a significant relationship between the level of corruption and forms of corruption in sport, $\chi^{2}(4)=12.62, p<0.01$. Match-fixing was the highest at 
the individual level $(n=41)$ and team level of corruptions $(n=13)$. At the organizational level of corruption, misuse of inside information was the highest $(n=6)$.

Table 1

Type of Sport Corruption According to Level of Corruption

\begin{tabular}{llllll}
\hline & & \multicolumn{3}{c}{ Level of corruption } \\
\cline { 3 - 6 } & & Individual & Team & Organization & Total \\
\hline \multirow{2}{*}{ Type of sport } & Match-fixing & 41 & 13 & 3 & 57 \\
corruption & Bribe & 10 & 0 & 2 & 12 \\
\multirow{2}{*}{ Total } & Misuse of inside information & 34 & 1 & 6 & 41 \\
\hline
\end{tabular}

To examine relationships among CPI, corruption in sport, and country that corruptions occurred, Pearson's correlation was conducted. Results of study showed that there was a positive correlation between CPI and Country $(r=0.33, n=110, p=0.00)$ at the alpha level of 0.05 . That is, the more corruptions occurred in society, the more people who are in public sectors (e.g., politicians, public officials) are likely to perceive the corruptions. Regarding the relationship between sport corruptions and CPI, there was a negative correlation ( $r=$ $-0.37, n=110, p=0.00$ ) at the alpha level of 0.05 . This indicates that politicians or public officials who have high level of perceptions on national corruptions are less likely to perceive corruptions occurred in sport. In terms of the relationships among intensity of corruption (i.e., period of the corruption), penalty (i.e., fine, disqualification), and the level of corruption (individual, team, and organization), no significant relationship was found.

To examine the mean differences of three levels of sport corruption (i.e., individual, team, organization) on CPI, one-way ANOVA was conducted and there was a significant mean difference of $\mathrm{CPI}(F(2,107)=5.34$, $p<0.006$, alpha $=0.05)$. Post hoc comparison using the Bonferroni test was performed to find specific group difference of the CPI and there was a significant mean difference of CPI between individual level of corruption $(M=6.64, S D=2.14)$ and team level of corruption $(M=4.90, S D=1.78)$.

\section{Discussion}

Corruption in sport is not unique topic anymore in the field of sport. Researchers (Gorse \& Chadwick, 2010; Maennig, 2005, 2008; Mason et al., 2006) have studied corruptions in sport, but little is known how people in public sectors (e.g., politicians, public officials) seriously perceive corruptions and how it is connected to corrupt behaviors in sport. This study aimed to examine the relationship between people's perceptions toward corruptions and magnitude of corruptions in a country, and the relationship between people's perceptions toward corruptions and sport corruptions. Results of study revealed match-fixing was the highest among three types of sport corruptions (i.e., match-fixing, bribe, misuse of inside information) at the individual and team level of corruption and misuse of inside information was the highest at the organizational level of corruption. This can be assumed that match-fixing was the highest at the individual and team level because it is the easiest way for individual athletes to receive big money in a short period of time by manipulating their performances.

Regarding relationships among CPI, magnitude of national corruption in a country, and sport corruptions, there was a positive correlation between CPI and the magnitude of corruption in a country and a negative correlation between CPI and sport corruptions. This means politicians and/or public officials who have high 
level of corruption perceptions are more likely to perceive national corruptions occurred in a country, but they are less likely to perceive sport related corruptions.

This study contributes to understanding types of sport corruption, hierarchical level of corruptions, and the relationship between perceptions toward national corruptions and sport corruption. In particular, this study provides practical implications with administrators in sport organizations in the sense that the results of study revealed how corruptions in sport are serious and how it negatively affects people's perceptions, and necessity of preventing sport corruptions for sport organizations. Corrupt behaviors in sport have been focused heavily on finding at the individual level (e.g., match-fixing) and team level (e.g., team doping), but it is not easy to find and reform organizational level of corruptions (e.g., misuse of inside information, bribe) due to difficulty of finding origin of the corruption. Thus, more strict and systematic penalty, and preventative programs for sport organizations should be considered.

Despite the contribution, this study has several limitations. This study attempted to understand overall corruptions in sport, including corruption types and motivations of corruption, only 110 cases were analyzed between 2000 and 2010. In other words, many of corruption cases that are not documented were not covered. In addition, this study used the concept of CPI to analyze the relationship between people's perceptions toward corruptions and sport corruptions, but CPI might not be the best way to examine the relationship because it is the concept that has been used only for measuring politicians' and public officials' perceptions toward national corruptions how to reform the corruption.

Therefore, future study will focus more on measuring the impact of corruption using more appropriate methods. To provide more practical implications with sport administrators, future research will also discuss how to reform and prevent corrupt behaviors in sport.

\section{References}

Andving, J. C., \& Fjeldstad, O. (2001). Corruption: A review of contemporary research (CMI Report R 2001:7). Bergen: Chr. Michelsen Institute.

Ashforth, B. E., \& Anand, V. (2003). The normalization of corruption in organizations. Research in Organizational Behavior, 25, $1-52$.

Bac, M. (1998). The scope, timing, and type of corruption. International Review of Law and Economics, 18, 101-120.

Becker, G. S., \& Stigler, G. J. (1974). Law enforcement, malfeasance, and compensation of enforcers. The Journal of Legal Studies, 1-18.

Brasz, H. A. (1970). The sociology of corruption. In A. J. Heidenheimer (Ed.), Political corruption: Readings in comparative analysis. N.Y.: Holt, Rinehart and Winston.

Collins, J. D., Uhlenbruck, K., \& Rodriguez, P. (2009). Why firms engage in corruption: A top management perspective. Journal of Business Ethics, 87, 89-108.

Gorse, S., \& Chadwick, S. (2010). Conceptualising corruption in sport: Implications for sponsorship programmes. The European Business Review, 2010, 40-45.

Hacker, F. (1981). Sozial psychologische Bedingungen der Korruption. In C. Brnner (Ed.), Korruption und Kontrolle. Böhlau, Wien.

Heidenheimer, A. J. (2002). Perspectives on the perception of corruption. In A. J. Heidenheimer, \& M. Johnston (Eds.), Political corruption: Concepts and contexts. N.J.: Transaction Publisher, New Brunswick.

Hüffling, C. (2002). Korruptionalssoziale Beziehung. Leske + Budrich, Opladen.

Huntington, S. P. (1989). Modernization and corruption. In A. J. Heidenheimer, \& M. Johnston (Eds.), Political corruption: A handbook (pp. 253-264). N.J.: Transaction Publishers, New Brunswick.

Khan, M. (1996). A Typology of corrupt transactions in developing countries. IDS Bulletin, 27, 12-21.

Maennig, W. (2005). Corruption in international sports and sport management: Forms, tendencies, extent and countermeasures. European Sport Management Quarterly, 5, 187-225. 
Maennig, W. (2008). Corruption in international sports and how it may be combatted. International Association of Sports Economists \& North American Association of Sports Economists, 08-13.

Mason, D. S., Thibault, L., \& Misener, L. (2006). An agency theory perspective on corruption in sport: The case of the International Olympic Committee. Journal of Sport Management, 20, 52-73.

Moore, C. (2008). Moral disengagement in processes of organizational corruption. Journal of Business Ethics, 80, 129-139.

Myint, U. (2000). Corruption: Causes, consequences and cures. Asia-Pacific Development Journal, 7.

Nye, J. S. (1967). Corruption and political development: A cost-benefit analysis. American Political Science Review, 61, 417-427.

Pinto, J., Leana, C. R., \& Pil, F. K. (2008). Corrupt organizations or organizations of corrupt individuals? Two types of organization-level corruption. Academy of Management Review, 33, 685-709.

Pitt, L. F., \& Abratt, R. (1986). Corruption in business-Are management attitudes right? Journal of Business Ethics, 5, 39-44.

Rabl, T., \& Kühlmann, T. M. (2008). Understanding corruption in organizations-Development and empirical assessment of an action model. Journal of Business Ethics, 82, 477-495.

Ramos, M. A. (2009). Game, set, match-fixing: Will international anti-doping initiatives pave the way for similar reform for corrupt betting in tennis? Houston Journal of International Law, 32, 202-244.

Tanzi, V. (1998). Corruption around the world: Causes, consequences, scope, and cures. Staff Papers-International Monetary Fund, 559-594.

Tanzi, V. (1995). Corruption, arm's-length relationships, and markets. In G. Fiorentini, \& S. Peltzman (Eds.), The economics of organised crime. Cambridge, M. A., Cambridge University Press.

Treisman, D. (2000). The causes of corruption: a cross-national study. Journal of Public Economics, 76, 399-457.

Urra, F. J. (2007). Assessing corruption: An analytical review of corruption measurement and its problems perception, error and utility. Edmund A. Walsh School of Foreign Service Georgetown University.

Van Duyne, P. C. (2001). Will caligula go transparent? Corruption in acts and attitudes. Forum on Crime and Society, 1, 73-95.

Von Arnim, H. H. (2003). Korruption in politik und verwaltung. In H. H. Von Arnim (Ed.), Korruption. netzwerke in politik: A mtern und wirtschaft. Knaur, München.

Zyglidopoulos, S. C., \& Fleming, P. J. (2008). Ethical distance in corrupt firms: How do innocent bystanders become guilty perpetrators? Journal of Business Ethics, 78, 265-274. 